Cite this: Chem. Commun., 2014 50, 5884

Received 16th March 2014 , Accepted 7th April 2014

DOI: $10.1039 / \mathrm{c} 4 \mathrm{cc} 01958 \mathrm{j}$

www.rsc.org/chemcomm

\section{A BODIPY-based reactive probe for the detection of $A u(I I I)$ species and its application to cell imaging ${ }^{\dagger}$}

\author{
Muhammed Üçüncü and Mustafa Emrullahoğlu*
}

\section{A BODIPY-based fluorescent probe bearing a pyridyl hydrazone motif responds selectively to $A u(I I)$ ions through an irreversible $\mathrm{C}=\mathrm{N}$ bond hydrolysis reaction.}

Gold species, besides their ability to catalyse chemical transformations in organic synthesis, ${ }^{1}$ have significant impacts on human health. ${ }^{2,3}$ Gold-based drugs have long been used in the treatment of rheumatoid arthritis and other autoimmune diseases. ${ }^{2}$ At the same time, when accumulated in the biological system at certain concentrations, gold species have the potential to disturb a series of cellular processes by irreversible interaction with biomolecules. ${ }^{3}$ In recent years, fluorescence-based sensing has become an indispensable tool for sensitive and accurate detection of trace levels of metal species in the solution. ${ }^{4}$ In addition, with the aid of fluorescence microscopy it has become possible to track metal species in living cells, which is of crucial importance for elucidating their roles in the biological system.

Recently, several gold ion selective molecular sensors based on various fluorophore units including rhodamine, ${ }^{5}$ BODIPY, ${ }^{6}$ fluorescein, ${ }^{7}$ and naphthalimide ${ }^{8}$ dyes have been reported in the literature. ${ }^{9}$ Given the challenge in design and synthesis, molecular sensors developed for gold species are reasonably few at the moment. The great majority of gold ion-specific molecular sensors reported to date share a common feature: the ability of gold ions to activate unsaturated bonds. In other words those sensors take advantage of the alkynophilic behaviour of gold species. The most prominent drawback of this type of sensing is the cross affinity with other alkynophilic metal species such as $\mathrm{Pd}^{2+}, \mathrm{Ni}^{2+}, \mathrm{Ag}^{+}, \mathrm{Cu}^{2+}$ and $\mathrm{Hg}^{2+}$. To avoid this handicap, new sensing strategies utilizing alternative recognition motifs are urgently sought.

Herein, we present the design, synthesis, spectral properties, and cell imaging studies of PyR-BOD, a novel turn-on type fluorescent

Department of Chemistry, Faculty of Science, Izmir Institute of Technology, Urla 35430, İmir, Turkey.E-mail: mustafaemrullahoglu@iyte.edu.tr $\dagger$ Electronic supplementary information (ESI) available: Absorbance and fluorescence data and all experimental procedures. See DOI: 10.1039/c4cc01958j

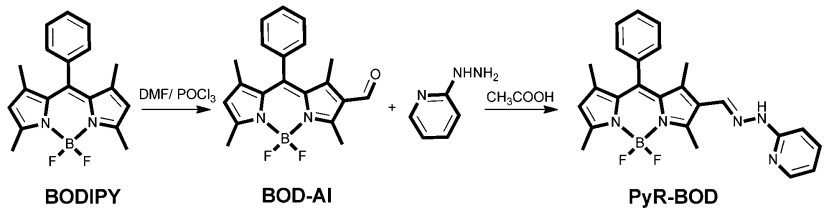

Scheme 1 Synthesis of the probe.

sensor that allows $\mathrm{Au}(\mathrm{III})$ ions to be detected on the basis of an irreversible $\mathrm{C}=\mathrm{N}$ bond hydrolysis-sensing mechanism. PyR-BOD was synthesized by the synthetic route outlined in Scheme 1, and the structure of the sensor was confirmed by ${ }^{1} \mathrm{H}-\mathrm{NMR},{ }^{13} \mathrm{C}-\mathrm{NMR}$ and mass spectrometry. In the first step, BOD-Al was synthesized via Vilsmeier Haack Formylation of the non-modified BODIPY. ${ }^{10}$ In the second step, BOD-Al was treated with 2-hydrazinopyridine in the presence of catalytic amount of glacial acetic acid to afford the title compound, PyR-BOD, in a good yield (68\%, overall). ${ }^{11}$

The structure of PyR-BOD, as displayed in Scheme 2, constitutes a BODIPY unit as the fluorophore and a pyridine hydrazone unit as the metal receptor site. Analyte specific fluorescent probes based on hydrazone derivatives of BODIPY dyes have been presented in the literature. ${ }^{12}$ In this investigation, given its high affinity to gold species, a pyridine motif was integrated to the BODIPY fluorophore in order to serve as the gold ion binding receptor. The BODIPY core was chosen as the signal reporter because of its exceptional photophysical properties such as high photo stability, high fluorescence quantum yield, robustness towards light and chemicals, and long emission/absorption wavelength. ${ }^{13}$

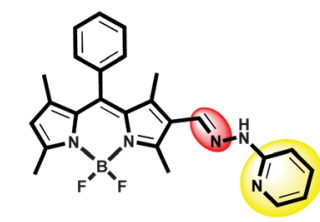

PyR-BOD

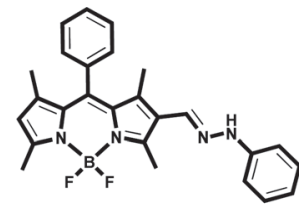

Ph-BOD

$$
\begin{gathered}
\lambda_{\text {ex }}=460 \mathrm{~nm} \\
\text { no emission }
\end{gathered}
$$

Scheme 2 Structure of the probe and the control probe. 
Importantly, PyR-BOD, was designed in such a way that the BODIPY fluorophore is non-emissive before the addition of any metal species. As displayed in Scheme 2, the $\mathrm{C}=\mathrm{N}$ functional group incorporated into the fluorophore diminishes the fluorescence emission because of a non-radiative deactivation process of the excited state via isomerization of the $\mathrm{C}=\mathrm{N}$ group. We envisioned that either blocking the isomerization of the $\mathrm{C}=\mathrm{N}$ bond by metal binding or directly hydrolysing it with a metal species would allow for the recovery of the BODIPY emission.

The fluorescence-sensing behaviour of PyR-BOD towards addition of $\mathrm{AuCl}_{3}$ was comprehensively surveyed upon excitation at $460 \mathrm{~nm}$. As shown in Fig. 1a, metal-free PyR-BOD was nonemissive due to a non-radiative deactivation process. As envisioned, the addition of $\mathrm{AuCl}_{3}(20 \mu \mathrm{M}, 2$ equiv.) to the probe solution $(0.1 \mathrm{M}$ phosphate buffer $\mathrm{pH} 7.0 / \mathrm{EtOH}, \mathrm{v} / \mathrm{v}, 1: 1$ ) resulted in a significant increase of the emission band centred at $512 \mathrm{~nm}$. The increase in the emission intensity was proportional to the amount of $\mathrm{Au}(\mathrm{III})$ with a good linear correlation and the minimum amount of $\mathrm{Au}$ (III) that can be detected under these conditions was evaluated to be $44 \mathrm{~nm}$ based on $\mathrm{S} / \mathrm{N}=3 .^{11}$ The emission intensity reached its maximum when 20 equiv. of $\mathrm{Au}(\mathrm{III})$ was added, with an enhancement factor over 300 fold. Notably, the spectroscopic response was fast and saturation of the emission intensity was observed within minutes (Fig. S8, ESI $\dagger$ ).

The UV-Vis spectra of PyR-BOD displayed a similar sensing behaviour towards the addition of $\mathrm{AuCl}_{3}$. The UV spectrum of metal-free PyR-BOD displayed one single absorption band at
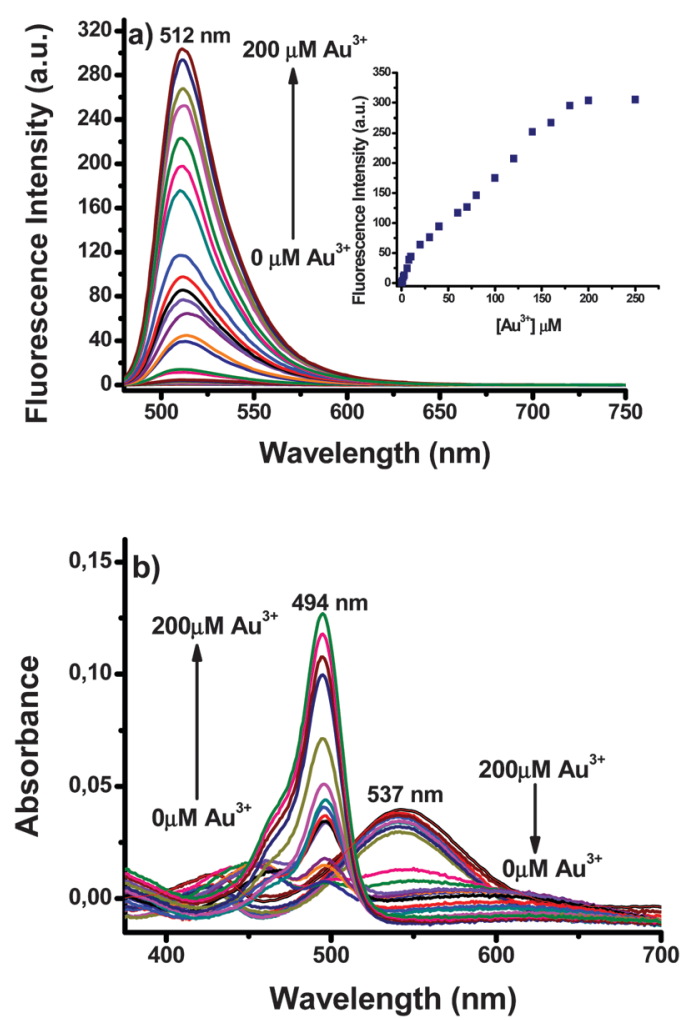

Fig. 1 (a) Fluorescence and (b) absorbance spectra of PyR-BOD $(10 \mu \mathrm{M})$ in the presence of increasing amount of $\mathrm{Au}^{3+}(0-200 \mu \mathrm{M})$ and $0.1 \mathrm{M}$ phosphate buffer/EtOH ( $\mathrm{pH} 7.0, \mathrm{v} / \mathrm{v}, 1: 1)$. Inset: calibration curve. ( $\lambda_{\mathrm{ex}}: 460 \mathrm{~nm}$ at $25^{\circ} \mathrm{C}$ ).
$537 \mathrm{~nm}$ belonging to the BODIPY core. In response to the addition of $\mathrm{Au}(\mathrm{III})$, this band disappeared concomitantly with the appearance of a new absorption band at $494 \mathrm{~nm}$ indicating a possible structural change of the BODIPY core (Fig. 1b). The blue shift of the absorption wavelength is reflected in a change in the colour of the solution from red to light orange. All spectral changes were easily detectable by the naked eye under visible light and UV lamp irradiation.

To our delight, no obvious spectral changes could be detected for the competing alkynophilic metal species such as $\mathrm{Ag}^{+}, \mathrm{Ni}^{2+}, \mathrm{Pd}^{2+}, \mathrm{Hg}^{2+}, \mathrm{Cu}^{2+}$, and for the other metal species such as $\mathrm{Mg}^{2+}, \mathrm{Mn}^{2+}, \mathrm{Pb}^{2+}, \mathrm{Zn}^{2+}, \mathrm{Cd}^{2+}, \mathrm{Fe}^{3+}, \mathrm{K}^{+}, \mathrm{Li}^{+}, \mathrm{Ba}^{2+}, \mathrm{Ca}^{2+}, \mathrm{Bi}^{3+}$, $\mathrm{In}^{3+}, \mathrm{Ce}^{3+}, \mathrm{Nd}^{3+}, \mathrm{Sm}^{3+}$. Especially notable was the observed selectivity for $\mathrm{Au}(\mathrm{III})$ over $\mathrm{Au}(\mathrm{I})$, which can be hardly seen for other gold ion responsive molecular sensors. Interference of other metal ions to the selectivity of PyR-BOD was also explored. The spectral response induced by $\mathrm{Au}(\mathrm{III})$ ions was not affected in the presence of any other metal species. ${ }^{11}$ These results indicated that PyR-BOD could properly detect Au(III) ions in the mixtures of other related species.

To check the reversibility of the sensing process, the probe solution PyR-BOD/Au ${ }^{3+}(1: 1)$ was treated with a cyanide ion source. The addition of $\mathrm{Bu}_{4} \mathrm{NCN}$ did not alter the emission pattern of PyR-BOD/ $/ \mathrm{Au}^{3+}$ indicating the sensing process to be irreversible in nature and based on a chemical reaction.

The outcome of the reaction-based sensing process could be easily monitored using Thin Layer Chromotography (TLC). ${ }^{11}$ The appearance of a green fluorescent compound on the TLC plate was a strong evidence for the formation of a new BODIPY derivate (Fig. S10, ESI $\dagger$ ). By the aid of NMR spectroscopy, the structure of this new compound was easily confirmed to be the hydrolysis product (BOD-Al) of PyR-BOD.

The sensing mechanism, as illustrated in scheme 3, is proposed to proceed via coordination of $\mathrm{Au}(\mathrm{III})$ to both pyridyl and imine nitrogen atoms forming an intermediate (PyR-BOD- $\mathrm{Au}^{3+}$ ), which is rapidly hydrolysed by the attack of water. Optimization experiments revealed that the content of water in the sensing media has a dramatic role in the sensing efficiency. ${ }^{11}$ While there were no spectral changes in pure organic solvent (i.e., ethanol), increasing the content of water in the sensing media $\left(\mathrm{H}_{2} \mathrm{O} / \mathrm{EtOH}, \mathrm{v} / \mathrm{v}, 1: 1\right)$ dramatically enhanced the response of the probe towards $\mathrm{Au}(\mathrm{III})$, which established the obvious need of water for the hydrolysis step. However, it is worth noting that, at higher percentages of water (e.g. $\left.\mathrm{H}_{2} \mathrm{O} / \mathrm{EtOH}, \mathrm{v} / \mathrm{v}, 9: 1\right)$, Au(III) loses its activity by forming aggregates in the solution.

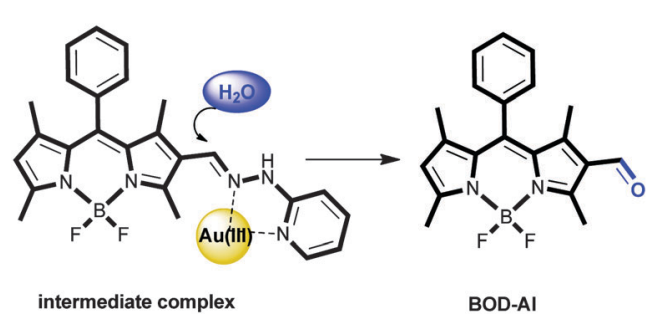

Scheme 3 Gold mediated hydrolysis of PyR-BOD 


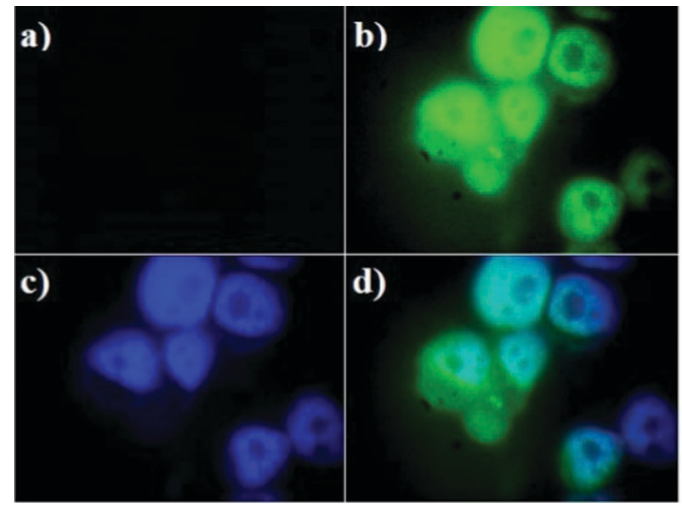

Fig. 2 Fluorescence images of Human Lung Adenocarcinoma cells (A549). (a) Fluorescence image of A549 cells treated with only PyR-BOD $(5 \mu \mathrm{M})$; (b) fluorescence image of cells treated with PyR-BOD $(5 \mu \mathrm{M})$ and $\mathrm{Au}^{3+}(10 \mu \mathrm{M})\left(\lambda_{\mathrm{ex}}=460 \mathrm{~nm}\right)$; (c) fluorescence image of cells treated with DAPI (control); (d) merged images of frames (b) and (c).

The effect of $\mathrm{pH}$ on the sensing process was investigated carefully. PyR-BOD displayed exceptional stability over a wide $\mathrm{pH}$ range, while remaining non-emissive over this range. Even in strong acidic and basic environments there were no indications for any decomposition of the probe structure. In the same way, the response of PyR-BOD towards the addition of Au(III) ions was not affected by changing the $\mathrm{pH}$ of sensing media (Fig. S3, ESI $\dagger$ ). Consequently, PyR-BOD operates efficiently over a wide $\mathrm{pH}$ range, ( $\mathrm{pH} 2-12)$, especially under physiological conditions, which is of primary importance for cell imaging studies.

A BODIPY derivative, Ph-BOD, lacking a pyridyl nitrogen atom on the phenyl ring, was prepared as an alternative sensor to PyR-BOD and to clarify the nature of the sensing process. Surprisingly, under the same sensing conditions probe Ph-BOD, even in the absence of any metal species, was not stable and hydrolysed rapidly to the corresponding aldehyde (Fig. S9, ESI $\dagger$ ). Given its instability, Ph-BOD could not be used further as a probe for gold analysis. Eventually, it turned out that the pyridyl nitrogen atom plays a superior role in selective binding of $\mathrm{Au}(\mathrm{III})$ ions, and also, in improving the overall efficiency of the sensing process.

Relying on the promising properties of PyR-BOD, we next questioned its potential for tracking Au(III) ions in living cells. A549 Human Lung Adenocarcinoma cells were incubated at $37{ }^{\circ} \mathrm{C}$ first with PyR-BOD $(5.0 \mu \mathrm{M})$ for $20 \mathrm{~min}$, followed by the addition of $\mathrm{Au}(\mathrm{III})(10 \mu \mathrm{M})$ and incubation for another $20 \mathrm{~min}$. Then, the cells were stained with a nucleus staining dye (DAPI $(1.0 \mathrm{mM}))$ for another $10 \mathrm{~min}$. With the aid of fluorescence microscopy, the turn-on response towards Au(III) was clearly monitored in the cells (Fig. 2). The fluorescence images of cells taken before and after the addition of $\mathrm{Au}(\mathrm{III})$ displayed a distinct fluorescence enhancement consistent with the results observed in the solution. Importantly, throughout the cell imaging process the cells were intact and showed a healthy spread and adherent morphology. This preliminary cell imaging study suggested that PyR-BOD is cell-membrane permeable and can be efficiently used for in vitro imaging of Au(III) in living cells.

In summary, we have developed a fluorescent molecular sensor that shows a turn-on type emission enhancement towards $\mathrm{Au}(\mathrm{III})$ ions with high sensitivity and selectivity over other metal ions. This novel probe operates through an irreversible $\mathrm{C}=\mathrm{N}$ hydrolysis reaction and thus can be classified as a chemodosimeter for $\mathrm{Au}(\mathrm{III})$ ions.

We thank İzmir Institute of Technology (IZTECH) and TUBTAK (113Z601) for financial support.

\section{Notes and references}

1 (a) I. Braun, A. M. Asiri and A. S. K. Hashmi, ACS Catal., 2013, 3, 1902; (b) Z. Li, C. Brouwer and C. He, Chem. Rev., 2008, 108, 3239; (c) A. Arcadi, Chem. Rev., 2008, 108, 3266; (d) A. S. K. Hashmi and M. Rudolph, Chem. Soc. Rev., 2008, 37, 1766; (e) N. Krause and C. Winter, Chem. Rev., 2011, 111, 1994.

2 (a) C. F. Shaw III, Chem. Rev., 1999, 99, 2589; (b) I. Ott, Coord. Chem. Rev., 2009, 253, 1670; (c) M. Navarro, Coord. Chem. Rev., 2009, 253, 1619.

3 (a) C. M. Goodman, C. D. McCusker, T. Yilmaz and V. M. Rotello, Bioconjugate Chem., 2004, 15, 897; (b) A. Habib and M. Tabata, J. Inorg. Biochem., 2004, 98, 1696.

4 (a) X. Li, X. Gao, W. Shi and H. Ma, Chem. Rev., 2014, 114, 590; (b) K. P. Carter, A. M. Young and A. E. Palmer, Chem. Rev., 2014, DOI: 10.1021/cr400546e; (c) X. Chen, T. Pradhan, F. Wang, J. S. Kim and J. Yoon, Chem. Rev., 2012, 112, 1910; (d) X. Su and I. Aprahamian, Chem. Soc. Rev., 2014, 43, 1963; (e) Z. Guo, S. Park, J. Yoon and I. Shin, Chem. Soc. Rev., 2014, 43, 16.

5 (a) M. J. Jou, X. Chen, K. M. K. Swamy, H. N. Kim, H.-J. Kim, S. G. Lee and J. Yoon, Chem. Commun., 2009, 7218; (b) O. A. Egorova, H. Seo, A. Chatterjee and K. H. Ahn, Org. Lett., 2010, 12, 401; (c) Y. K. Yang, S. Lee and J. Tae, Org. Lett., 2009, 11, 5610; (d) L. Yuan, W. Lin, Y. Yang and J. Song, Chem. Commun., 2011, 47, 4703; (e) M. Emrullahoğlu, E. Karakuş and M. Üçüncü, Analyst, 2013, 138, 3638.

6 (a) J.-B. Wang, Q.-Q. Wu, Y.-Z. Min, Y.-Z. Liu and Q.-H. Song, Chem. Commun., 2012, 48, 744; (b) E. Karakuş, M. Üçüncü and M. Emrullahoğlu, Chem. Commun., 2014, 50, 1119.

7 (a) H. Seo, M. E. Jun, O. A. Egorova, K. H. Lee, K. T. Kim and K. H. Ahn, Org. Lett., 2012, 14, 5062; (b) N. Y. Patil, V. S. Shinde, M. S. Thakare, P. H. Kumar, P. R. Bangal, A. K. Barui and C. R. Patra, Chem. Commun., 2012, 48, 11229.

8 (a) M. Dong, Y.-W. Wang and Y. Peng, Org. Lett., 2010, 12, 5310; (b) J. Y. Choi, G.-H. Kim, Z. Guo, H. Y. Lee, K. M. K. Swamy, J. Pai, S. Shin, I. Shin and J. Yoon, Biosens. Bioelectron., 2013, 49, 438.

9 (a) J. H. Do, H. N. Kim, J. Yoon, J. S. Kim and H.-J. Kim, Org. Lett., 2010, 12, 932; (b) Z. Öztaș, M. Pamuk and F. Algi, Tetrahedron, 2013, 69, 2048; (c) Y. Yang, C. Yin, F. Huo and J. Chao, RSC Adv., 2013, 3, 9637.

10 M. Isik, T. Ozdemir, I. S. Turan, S. Kolemen and E. U. Akkaya, Org. Lett., 2013, 15, 216.

11 See the $\mathrm{ESI} \dagger$ for more details.

12 (a) O. Dilek and S. L. Bane, Tetrahedron Lett., 2008, 49, 1413; (b) X.-J. Xiong, H. Wang, W.-B. Rao, X.-F. Guo and H.-S. Zhang, J. Chromatogr. A, 2010, 1217, 49; (c) O. Dilek and S. L. Bane, J. Fluoresc., 2011, 21, 347; (d) Q. Li, Y. Yue, Y. Guo and S. Shao, Sens. Actuators, B, 2012, 173, 797; (e) O. G. Tsay, S. T. Manjare, H. Kim, K. M. Lee, Y. S. Lee and D. G. Churchill, Inorg. Chem., 2013, 52, 10052.

13 (a) N. Boens, V. Leen and W. Dehaen, Chem. Soc. Rev., 2012, 41, 1130; (b) R. Ziessel, G. Ulrich and A. Harriman, New J. Chem., 2007, 31, 496; (c) A. Loudet and K. Burgess, Chem. Rev., 2007, 107, 4891; (d) G. Ulrich, R. Ziessel and A. Harriman, Angew. Chem., Int. Ed., 2008, 47, 1184. 